$=10^{-3} \mathrm{~kg} \mathrm{~mol}^{-1}$ ), will continue in use as an accepted decimal sub-multiple of the SI unit. However, the SI unit itself is suitable for expressing values of the molar mass for macromolecular substances. Thus, one could add to Dr Edsall's equivalent statements the alternative : "the molar mass of protein $\mathrm{X}$ is $25 \mathrm{~kg}$ $\mathrm{mol}^{-1}$ ".

Although the unit of mass, "unified atomic mass unit", is outside the SI, it has been recognized by the CIPM as useful in specialized fields of scientific research ${ }^{1}$. Its value expressed in the SI unit, the kilogram, is derived by experiment and is therefore not known exactly. Although in general one should be chary of proliferating special names, the present name for this unit, even when contracted to "atomic mass unit" (the term "unified" distinguishing it from slightly different earlier units based on ${ }^{16} \mathrm{O}$ and on $\mathrm{O}=16$ ), is not notably convenient or informative. Dr Edsall's suggestion that it be renamed the dalton merits consideration by the international agencies concerned with standardization of chemical and physical nomenclature so long as the unit itself continues to be recognized by the CIPM as one of those useful outside the SI in specialized fields. It would not be helpful if scientists in different fields employed different names for the same unit.

Yours faithfully,

Martin A. Paul

Division of Chemistry and

Chemical Technology,

National Academy of Sciences-

National Research Council,

Washington, DC 20418, USA

1 The International System of Units (SI), translation approved by the International Bureau of Weights and Measures of its publication, Le Système International d'Unités, prepared jointly and published independently by the National Physical Laboratory, UK, and the National Bureau of Standards, USA: National Bureau of Standards Special Publication 330, 1970, US Government Printing Office, Washington, DC 20402.

\section{Definition of Intelligence}

SIR,--Because others (Nature, 228, 1008; 1970) have commented on the definition of intelligence put forward by Fatmi and Young (Nature, 228, 97; 1970) and subsequently extended by myself (Nature, 228, 589; 1970), I would like to make some further observations.

With regard to the letter from P. M. Muller, the process of induction would be covered by my own definition, as would "synthetic a priori". However, processes of reasoning from the part to the whole, from the particular to the general, and from the individual to the universal, are not identical and isomorphic processes, nor are they symmetrical with respect to deduction and induction.

If we accept Gödel's theorem, a single, finite automaton with a phrase-structure grammar can be either complete and consistent (closed) or universal (open). A Gödel complete system will accept only tautologies or empirically verifiable sensedata that have been specified in the instruction set, rejecting all other inputs as illogicality or "noise". The possibility of new or unspecified states is excluded. If we assume that human intelligence not only construes syllogisms, but also discovers, elucidates and initiates the previously unknown, then it is clear that this cannot be a property of Gödel complete automata (existing computers). Indeed, it would seem that an incomplete instruction set (a quasi-nondeterministic system) is a necessary condition for the emergence and evolution of intelligence, as we observe it in living systems. However, the possibilities of machines do not end with single finitestate machines or with phrase-structure grammars.

In my own work I have been considering the possibilities of hierarchical networks of automata, some of them backward deterministic ${ }^{1}$, in an attempt to solve the Gödel theorem problem for quasi-non-deterministic systems, including brain-models. The basic idea is to axiomatize the levels of the system independently and use negative feedback to control the universality (requisite variety) of both individual levels and the system as a whole. An essential part of the control system is an order : disorder detector, as suggested by $\mathbf{H}$. B. Barlow in his letter. This type of system would also imply that the original definition of Fatmi and Young would be too broad to draw a valid distinction between men and machines.

With regard to the letter from $H$. A. Cook. Any system is quantifiable if one knows what to measure and how to measure it. It is another matter to decide whether such a quantification provides an adequate description of the system as a whole. The informationtheoretic brain model mentioned above implies a physiological symbol-processing mechanism in the brain, which could form a substrate for the heritable components of both intelligence and linguistic behaviour. Since such a component would be determined by input-rate and digitspan, and would be invariant with respect to learning, it should be possible to isolate and quantify it given a calibrated digital input and criteria for assessing the output response in quantitative terms. With regard to a quantified definition of intelligence, without recourse to linguistic behaviour, we may be up against a special case of Richard's paradox.

The correspondence following Fatmi and Young's original letter has emphasized the need for further dialogue concerning the theoretical and philosophical aspects of machine and human intelligence, and it is gratifying to learn that the Cambridge Branch of the Brain Research Association is setting up a forum in this area of study.

\section{Yours faithfully, GORDON HYDE}

11 The Close,

Dunmow, Essex CM6 $1 \mathrm{EW}$

1 Wang How, $A$ Survey of Mathematical Logic, 175 (North-Holland, 1964).

\section{Obituary}

\section{Dr J. E. Falk}

JoHN EDWIN FALK, chief of the division of plant industry, Commonwealth Scientific and Industrial Research Organization, Canberra, died on October 25, 1970. Born in 1917 at Cessnock, NSW, he studied pharmacy at the University of Sydney, but finding that his interests lay in chemistry he completed a Bachelor of Science degree in 1942. After graduating he joined Professor V. M. Trikojus in an investigation of synthetic methods of preparation of essential drugs unavailable in war time Australia. In 1944 he became Chief Chemist at Bayer's in Sydney and at the end of the war returned to research in the university on a Wellcome fellowship under Professor Adrian Albert. During this period his research into the mode of action of certain antimalarial drugs awakened his interest in biochemistry and led him into the field of haem pigments. In 1947 he was awarded a grant by the National Health and Medical Research Council to work at the Royal North Shore Hospital, Sydney, under Professor M. R. Lemberg, FRS. Here he investigated the prosthetic group of cytochrome oxidase and learnt a great deal about porphyrins.

In 1948, Falk was granted a Nuffield travelling fellowship and with financial assistance from the National Health and Medical Research Council he went to University College Hospital Medical School in London to work with Professor C. Rimington, FRS. His research included a systematic study of the infrared spectra of porphyrins and haems as well as further work on cytochrome oxidase. He received his $\mathrm{PhD}$ in 1951. A "Nuffield Unit of Pyrrole Pigment Research" was established in Professor Rimington's department and Falk was appointed director. In 1953, he was awarded a Foulerton research fellowship by the Royal Society. During this period, he developed analytical methods for porphyrins and turned his attention 